\title{
Stature estimation in Malaysian population from radiographic measurements of upper limbs
}

\author{
Normaizatul Afizah Ismail ${ }^{1,2}$, Norakmal Hisyam Abd Khupur ${ }^{3}$, Khairul Osman $^{3}$, Ab Halim Mansar ${ }^{4}$,
} Mohamed Swarhib Shafie ${ }^{2}$ and Faridah Mohd Nor $^{2 *}$

\begin{abstract}
Background: Stature is one of the important aspects of biological profile for an unknown individual in forensic anthropology. As stature is population-specific, this study was conducted in Hospital Sungai Buloh, Hospital Tapah and Hospital Kampar to develop regression for stature estimation in the Malaysian population. About 90 subjects from 23 to 47 years old were selected for radiography of upper limbs. The standing height of the subject was measured beforehand for each subject. The maximum length of the bones was measured on the $x$-ray film in $\mathrm{cm}$, and analysis was performed by SPSS version 23.

Results: Results showed significant correlations between stature and upper limb bones $(p<0.05)$. There was significant difference between males and females in stature $(p<0.05)$. However, there was no significant difference found in stature among age and demic groups ( $p>0.05$ ). About eight regression equations were developed, of which three for single bone and one in combination of three bones in males and females. The regression equations with combination of bones showed the highest correlation coefficient (r). However, these regression equations are not suitable yet to be used practically in Malaysian population due to high standard error of estimates.
\end{abstract}

Conclusion: In brief, the research study has to be validated with a larger sample size to represent the Malaysian population.

Keywords: Stature, Radiography, Bone, Upper limbs

\section{Background}

The science of estimating stature from bones was well known since the 19th century (Pearson 1899) till present moment. Researchers all over the world developed regression for different populations. Long bones, metacarpals, metatarsals, vertebrae, talus, calcaneus, scapula, pelvis and skull were proven to show correlation with stature (Bidmos 2006; Karaman et al. 2008; Karakas et al. 2011; Mahakkanukrauh et al. 2011; Giurazza et al. 2012; Torimitsu et al. 2014a, 2014b; Zhang et al. 2015). Though a variety of bones were used to estimate stature, estimation of stature from long bones appeared to be most popularly used and provided accurate results (Dupertuis and Hadden 1951; Trotter and Gleser 1952;

\footnotetext{
* Correspondence: mnfaridah@gmail.com

${ }^{2}$ Pathology Department, Universiti Kebangsaan Malaysia Medical Centre,

Kuala Lumpur, Malaysia

Full list of author information is available at the end of the article
}

Mall et al. 2001; Radoinova et al. 2002; Hauser et al. 2005; Celbis and Agritmis 2006; Dayal et al. 2008; Didia et al. 2009; Mahakkanukrauh et al. 2011; Akhlaghi et al. 2012; Ahmed 2013a, 2013b; Farsinejad et al. 2014; Torimitsu et al. 2014c; Jeong and Jantz 2016; Zech et al. 2016).

Early publications on stature estimation developed by Pearson (1899), Trotter and Gleser (1952) and Trotter and Gleser (1958) were widely used by several researchers. However, in the present day, these regressions were no longer valid to represent different populations and generations. Their applications could lead to inaccuracy in stature estimation in the current forensic setting (Radoinova et al. 2002). The most precise results for estimating stature should be provided by the population, from which the equations were derived. Thus, each population should have their own regressions with a sampling of modern populations to account for any secular trends in stature (Mahakkanukrauh et al. 2011). 
There were various methods used by researchers for stature estimation depending on the available resources. Most researchers used direct measurements on bones such as the Terry's collection (Hunt and Albanese 2005), Dart's collection (Dayal et al. 2009), Giraudi's collection (Giraudi et al. 1984) and Hamann-Todd's collection (Mensforth and Latimer 1989). Recent studies used x-ray and scan due to the new upcoming technology and availability of skeletal collections (Muñoz et al. 2001; Sarajlić et al. 2006; Petrovečki et al. 2007; Hasegawa et al. 2009; Amal Hayati et al. 2011; Farsinejad et al. 2014). The most advanced method was to perform post mortem computed tomography (PMCT), as it is in line with the growing use of virtual autopsy worldwide (Giurazza et al. 2012; Giurazza et al. 2013; Torimitsu et al. 2014a, 2014b; Hishmat et al. 2015; Zhang et al. 2015). Although direct measurements on bones gave more accurate results compared to that with radiography (Hauser et al. 2005), direct measurement has not been adopted in Malaysia due to the limited number of skeletal collections.

Estimation of stature is an important indicator to help in establishing the biological profile of skeletal remains in medicolegal investigations. In this study, predictive formulae were constructed based on radiographic measurements of maximum length of humerus, radius and ulna. The aim of this study was to develop regression equations to estimate stature of Malaysian adults from radiographic measurements of upper limbs.

\section{Materials and methods}

\section{Subjects}

A total of 90 healthy Malaysian adults comprised 50 males and 40 females, from 23 to 47 years of ages, were randomly selected from the Radiology Department. The ethical approval was obtained from the Institutional Ethics Committee (NMRR-09-1040-4976). Consent from all subjects was obtained prior to the study. Subjects with history of trauma, surgery of upper limb and/or past history of prolonged illness were excluded from the study. The living stature of the subject was measured by using the standard height measurement scale (Portable Leicester Stadiometer) taken in centimetre $(\mathrm{cm})$ (in two decimal places). The subjects were required to stand erect in an anatomical position (Saladin 2007). As the diversity in demic groups is challenging, ambiguous or mixed demic groups were excluded as studies proved that genetic and dietary may contribute to the difference in body build and growth (Shields 2007).

\section{Radiographic technique for bone measurement}

The X-rays for left and right hands were taken for each subject. A custom-made aluminium ruler scale $(49 \mathrm{~cm}$ long, $47 \mathrm{~cm}$ length) was placed on the scanning film alongside the upper limb for measurements. The position of the side marker (left or right) against the feature was marked, and the exposure limit was set at 40 to $50 \mathrm{kvp}$ (kilovoltage peak) or 4 to $5 \mathrm{mAs}$ (miliamperage per second).

The maximum length of humerus was measured from the head of the humerus to trochlea. The maximum length of radius was taken from radial head to the tip of the styloid process. The maximum length of ulna was taken from olecranon to the tip of styloid process. All measurements on both sides were recorded in $\mathrm{cm}$ (two decimal places) (Saladin 2007).

\section{Statistical analysis}

The data was analysed by SPSS version 23.0 for Windows. The descriptive statistics were analysed by One-way ANOVA (post-hoc) to evaluate, whether the means of all groups (Malays, Chinese and Indians) was different for different parameters (lengths of humerus, radius and ulna). The Shapiro Wilk test was used to determine if the three data sets showed a normal distribution. The Pearson's correlation analysis was used to see the correlations between stature and the parameters. Single and multiple regression analysis were used to predict stature based on single and multiple parameters, respectively. Only measurements from the left side were accounted for in the regression equation analysis. The right side measurement was used, only when the left side was not available due to fractures or deformity. The study was validated by testing the regression against 10 randomly selected subjects for comparison with true stature.

\section{Results}

The Shapiro-Wilk test showed that the data $(n=90)$ were normally distributed. The males $(n=50)$ were subcategorised into three different demic groups (Malay $=20$, Chinese $=7$, Indian $=23)$. Similarly, the females $(n=40)$ were subcategorised into three demic groups (Malay $=20$, Chinese $=7$, Indian $=23$ ). Results showed that stature was significantly different between male and female $(p<0.05)$. The mean stature of male was $168.24 \mathrm{~cm}$, which was higher than the female $(155.69 \mathrm{~cm})$. However, there was no significant difference among the demic groups of Malay, Chinese and Indian in stature $(p>0.05)$.

There was no significant difference in stature with age or with different sides of the body. The minimum and maximum ages for males were 23 years and 47 years, respectively. In females, the minimum and maximum ages were 23 years and 44 years, respectively. The age distribution was normal. The results showed that with increased age, the stature did not increase in persons between 23 and 47 years of age.

The Pearson's correlation showed that stature was correlated with all the parameters namely, maximum lengths of humerus, radius and ulna $(p<0.05)$. The minimum, maximum and mean values for all measurements 
and living stature were tabulated (Table 1). The regression equations for stature estimation were presented (Table 2). The single linear regression equations were developed if there was only one bone available for stature estimation. The multiple regression equations were developed for multiple bones to increase its accuracy.

In different sex, the correlation differed in several aspects for instance, humerus showed the highest correlation $(r=0.64)$ with stature in female, but showed the least correlation $(r=0.44)$ in males for single linear regression equations. However, when humerus, radius and ulna were used in combination, the correlation coefficient was high in both sexes $(r=0.71$ in male, $r=0.72$ in female). The regression equation with the highest accuracy was indicated by the lowest standard error of estimate $(S E E)$. In simple linear regression, the lowest $S E E$ was based on radius in female $(S E E=10.33)$. In multiple regression, the highest correlation with stature was achieved in female $(r=0.72)$.

For comparison, the mean of estimated stature was compared with the mean of true stature by paired $T$-test (Table 3). The results showed no significant difference between true and estimated stature in both single and multiple regressions (Table 4). The statistical results indicated that estimated statures were in good approximation with true statures. The maximum difference between true and estimated stature in both single linear and multiple regression equations showed large differences i.e. 8.96 and $9.33 \mathrm{~cm}$, respectively.

\section{Discussion}

In the present study, Malaysian males were found to be taller than females. Results showed significant differences in stature between males and females. There was no difference among the demic groups of Malay, Chinese and Indian. The results were in accordance with a study in similar population using radiograph on lower limbs (Amal Hayati et al. 2011). The agreement of results between this study and the literature was probably attributed to similar population used and their small sample size. Interestingly, the demic groups in Malaysia are

Table 1 Descriptive Statistics of Measurements

\begin{tabular}{lllllll}
\hline & & $N$ & Minimum & Maximum & Mean & Std. Deviation \\
\hline Stature & Male & 50 & 149.55 & 188.35 & 168.24 & 6.93 \\
& Female & 40 & 142.20 & 166.60 & 155.69 & 5.78 \\
Humerus & Male & 50 & 26.15 & 33.35 & 30.66 & 1.72 \\
& Female & 40 & 22.40 & 31.25 & 27.71 & 1.74 \\
\multirow{4}{*}{ Radius } & Male & 50 & 24.85 & 31.60 & 28.92 & 1.69 \\
& Female & 40 & 20.75 & 29.70 & 26.03 & 1.94 \\
\multirow{2}{*}{ Ulna } & Male & 50 & 24.95 & 33.25 & 29.28 & 1.69 \\
& Female & 40 & 21.60 & 29.40 & 26.56 & 1.79 \\
\hline
\end{tabular}

Table 2 Regression equations for male and female

\begin{tabular}{|c|c|c|c|c|c|c|c|}
\hline & Regression & & & SEE & $\mathrm{R}$ & $R^{2}$ & $\mathrm{~F}$ \\
\hline \multicolumn{8}{|l|}{ Male } \\
\hline Stature & 113.657 & + & $1.780 \mathrm{Hu}$ & \pm 15.99 & 0.44 & 0.20 & 11.69 \\
\hline Stature & 89.816 & + & $2.711 \mathrm{Ra}$ & \pm 12.82 & 0.66 & 0.44 & 37.54 \\
\hline Stature & 87.148 & + & $2.769 \mathrm{U}$ & \pm 12.73 & 0.68 & 0.46 & 40.73 \\
\hline Stature & 71.021 & + & $\begin{array}{l}\text { (0.691 Hu } \\
+1.025 \mathrm{Ra} \\
+1.584 \mathrm{U})\end{array}$ & \pm 15.10 & 0.71 & 0.50 & 15.61 \\
\hline \multicolumn{8}{|l|}{ Female } \\
\hline Stature & 97.196 & + & $2.111 \mathrm{Hu}$ & \pm 11.51 & 0.64 & 0.40 & 25.91 \\
\hline Stature & 111.424 & + & $1.700 \mathrm{Ra}$ & \pm 10.33 & 0.57 & 0.33 & 18.48 \\
\hline Stature & 104.415 & + & $1.931 \mathrm{U}$ & \pm 11.96 & 0.60 & 0.36 & 21.02 \\
\hline Stature & 82.116 & + & $\begin{array}{l}(0.905 \mathrm{Hu} \\
+0.377 \mathrm{Ra} \\
+1.433 \mathrm{U})\end{array}$ & \pm 11.96 & 0.72 & 0.52 & 12.73 \\
\hline
\end{tabular}

Hu Humerus, $R a$ radius, $U$ Ulna

complex in nature as some Malaysians were descendants from mixed marriage. For instance, Chindian is an offspring of Chinese and Indian. This information was missed during the study as the family tree was excluded from the profile of each subject.

Small sample size $(n=90)$ was a limitation in this study. However, it is a common issue in stature estimation studies. Several studies were done on limited number of sample populations. For instance, studies were done in the Croatian population $(n=40)$, Bosnian $(n=50)$, Iranian $(n=101)$ and Spain population $(n=104)$ (Petrovečki et al. 2007; Sarajlić et al. 2006; Farsinejad et al. 2014; Muñoz et al. 2001). It is noteworthy that these were preliminary studies, which require further research for validation. Additionally, a study on the Japanese population used a relatively big sample size $(n=434)$, which is commendable (Hasegawa et al. 2009).

The present study proved that anthropometric measurements did not show any difference between the left

Table 3 Comparison of true stature with estimated stature using linear regression and multiple regression equations

\begin{tabular}{llllllll}
\hline $\mathrm{Hu}$ & $\mathrm{Ra}$ & $\mathrm{U}$ & $\begin{array}{l}\text { True } \\
\text { stature }\end{array}$ & $\begin{array}{l}\text { Stature } \\
\text { using } \\
\text { single } \\
\text { regression }\end{array}$ & Differences & $\begin{array}{l}\text { Stature } \\
\text { using } \\
\text { multiple } \\
\text { regression }\end{array}$ & Differences \\
\hline 28.6 & 22.65 & 24.15 & 154.00 & 149.93 & -4.07 & 147.12 & -6.88 \\
29.2 & 23.05 & 24.75 & 158.00 & 150.61 & -7.39 & 148.67 & -9.33 \\
24.6 & 20.75 & 21.6 & 142.20 & 146.70 & 4.50 & 140.44 & -1.76 \\
28.75 & 27.65 & 28.2 & 164.40 & 158.43 & -5.97 & 158.47 & -5.93 \\
29.2 & 28.6 & 28.2 & 162.60 & 160.04 & -2.56 & 158.83 & -3.77 \\
27.6 & 24.45 & 25.6 & 152.45 & 152.99 & 0.54 & 151.19 & -1.26 \\
28.6 & 26.6 & 29.25 & 156.65 & 156.64 & -0.01 & 160.53 & 3.88 \\
27.65 & 26.4 & 28.1 & 160.00 & 156.30 & -3.70 & 157.77 & -2.23 \\
25.8 & 24.2 & 23.3 & 143.60 & 152.56 & 8.96 & 145.71 & 2.11 \\
26.2 & 28.6 & 28.25 & 158.35 & 160.04 & 1.69 & 158.95 & 0.60 \\
\hline
\end{tabular}


Table 4 Paired T-test between true and estimated stature

\begin{tabular}{|c|c|c|c|c|c|c|c|c|}
\hline \multicolumn{9}{|l|}{ Paired Samples T-Test } \\
\hline & \multicolumn{5}{|c|}{ Paired Differences } & \multirow[t]{3}{*}{$\mathrm{t}$} & \multirow[t]{3}{*}{ df } & \multirow{3}{*}{$\begin{array}{l}\text { Sig. } \\
\text { (2-tailed) }\end{array}$} \\
\hline & \multirow[t]{2}{*}{ Mean } & \multirow[t]{2}{*}{ Std. Deviation } & \multirow[t]{2}{*}{ Std. Error Mean } & \multicolumn{2}{|c|}{ 95\% Confidence Interval of the Difference } & & & \\
\hline & & & & Lower & Upper & & & \\
\hline $\begin{array}{ll}\text { Pair } 1 \text { True stature - Est stature (single) } \\
\text {. }\end{array}$ & .80 & 4.99 & 1.57 & -2.77 & 4.37 & .507 & 9 & .62 \\
\hline Pair 2 True stature - Est stature (multiple) & 2.45 & 4.12 & 1.30 & -.49 & 5.40 & 1.89 & 9 & .09 \\
\hline
\end{tabular}

or right arm. The literature showed no difference between different sides of the arm (Trotter and Gleser 1952; Petrovečki et al. 2007; Hasegawa et al. 2009; Amal Hayati et al. 2011). Thus, this research used only the left arm to develop regressions. Several studies used only one side measurement (Choi et al. 1997; Muñoz et al. 2001; Amal Hayati et al. 2011; Farsinejad et al. 2014). In the literature, the average values of both sides were used to develop regressions (Radoinova et al. 2002; Sarajlić et al. 2006; Petrovečki et al. 2007; Hasegawa et al. 2009). Also, a study proved that bilateral asymmetry existed whereby, the farmers tend to have stronger hands on the dominant side because of routine extraneous exercise (Krishan et al. 2010). Thus, it is feasible to analyse both sides of extremities before taking into account, whether to use a single side or an average of both sides in developing regressions for a specific population.

In the literature, lower limbs were highly correlated with stature than the upper limbs (Trotter and Gleser 1952; Choi et al. 1997; Muñoz et al. 2001; Duyar and Pelin 2003; Hasegawa et al. 2009; Amal Hayati et al. 2011; Giurazza et al. 2012). However, in most cases, the lower limbs were sometimes went missing, fractured and/or damaged at the time of discovery (Giurazza et al. 2012). In such conditions, upper limbs could provide alternatives for stature estimation. In this research, the best bone to be used was ulna in male $(r=0.68)$ and humerus in female $(r=0.64)$. Interestingly, Petrovečki et al. (2007) found similar results in female $(r=0.50)$.

The utility of regression equation depends heavily on $S E E$ value. The SEE in this study ranged from 10.33 to 15.99, which was higher than that in the literature (Table 5). However, the SEE in this study was comparable

Table 5 Comparison of Standard Error of Estimate (SEE) with other similar studies using $\mathrm{x}$-ray on long bones

\begin{tabular}{ll}
\hline Research & SEE (cm) \\
\hline Sarajlić et al. (2006) & 3.48 to 4.44 \\
Petrovečki et al. (2007) & 2.00 to 5.21 \\
Hasegawa et al. (2009) & 2.63 to 4.45 \\
Farsinejad et al. (2014) & 3.6 to 3.9 \\
Amal Hayati et al. (2011) & 14.78 to 18.73 \\
This study & 10.33 to 15.99 \\
\hline
\end{tabular}

with a study done in the Malaysian population (Amal Hayati et al. 2011). Both studies had limited sample size. Amal Hayati et al. (2011) utilised only 32 subjects, and this study used 90 subjects. This present study was a preliminary study in the Malaysian population. The regression equations are not suitable yet to be used practically in Malaysian population due to high standard error of estimates. However, this study showed a great effort to develop regression equations for the Malaysian population. The regression can be developed further with extended sample size to provide reliable regression for stature estimation in the Malaysian population.

\section{Conclusion}

In conclusion, regression equations were developed for stature estimation in male and female based on humerus, radius and ulna. The best parameters were ulna (in male) and humerus (in female). However, the regressions could be improved in future with larger sample size to better represent the diversity of the population. We will continue this research to validate the results in an extended sample for identification of human remains in Malaysia.

Abbreviations

cm: Centimetre; kvp: Kilovoltage peak; mAs: Miliamperage per second

\section{Acknowledgements}

Special thanks and sincere appreciation to the Directors of Hospital Sungai Buloh, Hospital Tapah, and Hospital Kampar. Special gratitude goes to all the subjects, who had given full cooperation in the conduct of the study.

Funding

None.

Availability of data and materials

Data will not be shared with public access.

Authors' contributions

NAI and NHAK: Data collector. KO: SPSS analyst. AHM and MSS: Check manuscript and give information. All authors read and approved the final manuscript.

Ethical approval and consent to participate

Ethical clearance was obtained from Ministry of Health, Malaysia (NMRR09-1040-4976).

Consent for publication

Consent forms were given and signed by all subjects prior to participation.

Competing interests

The authors declare that they have no competing interests. 


\section{Publisher's Note}

Springer Nature remains neutral with regard to jurisdictional claims in published maps and institutional affiliations.

\section{Author details}

'Kolej Universiti INSANIAH, Kuala Ketil, Kedah, Malaysia. ${ }^{2}$ Pathology Department, Universiti Kebangsaan Malaysia Medical Centre, Kuala Lumpur, Malaysia. ${ }^{3}$ Forensic Science Programme, Universiti Kebangsaan Malaysia, Kuala Lumpur, Malaysia. ${ }^{4}$ Segi College, Kuala Lumpur, Malaysia.

\section{Received: 3 November 2017 Accepted: 22 February 2018}

\section{Published online: 27 February 2018}

\section{References}

Ahmed AA (2013a) Estimation of stature from the upper limb measurements of Sudanese adults. Forensic Sci Int 228(1-3):178.e1-178.e7

Ahmed AA (2013b) Estimation of stature using lower limb measurements in Sudanese Arabs. J Forensic Legal Med 20(5):483-488

Akhlaghi M, Hajibeygi M, Zamani N, Moradi B (2012) Estimation of stature from upper limb anthropometry in Iranian population. J Forensic Legal Med 19(5): 280-284

Amal Hayati ZA, Khairul O, Sri Pawita Albakri AH, Noor Hazfalinda H, Normaizatul Afizah I (2011) Stature approximation of Malays, Chinese and Indian in Malaysia using radiographs of Femur, Tibia and Fibula. Malays J Health Sci 9(1):45-50

Bidmos M (2006) Adult stature reconstruction from the calcaneus of South Africans of European descent. J Clin Forensic Med 13(5):247-252

Celbis O, Agritmis H (2006) Estimation of stature and determination of sex from radial and ulnar bone lengths in a Turkish corpse sample. Forensic Sci Int 158(2-3):135-139

Choi BY, Chae YM, Chung IH, Kang HS (1997) Correlation between post-mortem stature and the dried limb-bone lengths of Korean adult males. Yonsei Med $J$ 38(2):79-85

Dayal MR, Kegley ADT, Štrkalj G, Bidmos MA, Kuykendall KL (2009) The history and composition of the Raymond A. Dart collection of human skeletons at the University of the Witwatersrand, Johannesburg, South Africa. Am J Phys Anthropol 140(2):324-335

Dayal MR, Steyn M, Kuykendall KL (2008) Stature estimation from bones of South African whites. S Afr J Sci 104:124-128

Didia BC, Nduka EC, Adele O (2009) Stature estimation formulae for Nigerians. J Forensic Sci 54(1):20-21

Dupertuis CW, Hadden JA (1951) On the reconstruction of stature from long bones. Am J Phys Anthropol 9(1):15-54

Duyar I, Pelin C (2003) Body height estimation based on tibia length in different stature groups. Am J Phys Anthropol 122(1):23-27

Farsinejad M, Rasaneh S, Zamani N, Jamshidi F (2014) Relationship between the stature and the length of long bones measured from the X-rays; modifed trotter and gleser formulae in Iranian population: a preliminary report. Soud Lek 59(2):20-11

Giraudi R, Fissore F, Giacobini G (1984) The collection of human skulls and postcranial skeletons at the Department of Human Anatomy of the University of Torino (Italy). Am J Phys Anthropol 65(2):105-107

Giurazza F, Del Vescovo R, Schena E, Battisti S, Cazzato RL, Grasso FR, Silvestri S, Denaro V, Zobel BB (2012) Determination of stature from skeletal and skull measurements by CT scan evaluation. Forensic Sci Int 222(1-3):398.e1-398.e9

Giurazza F, Del Vescovo R, Schena E, Cazzato RL, D'Agostino F, Grasso RF, Silvestri S, Zobel BB (2013) Stature estimation from scapular measurements by CT scan evaluation in an Italian population. Legal Med 15(4):202-208

Hasegawa I, Uenishi K, Fukunaga T, Kimura R, Osawa M (2009) Stature estimation formulae from radiographically determined limb bone length in a modern Japanese population. Legal Med 11(6):260-266

Hauser R, Smoliński J, Gos T (2005) The estimation of stature on the basis of measurements of the femur. Forensic Sci Int 147(2-3):185-190

Hishmat AM, Michiue T, Sogawa N, Oritani S, Ishikawa T, Fawzy IA, Hashem MAM, Maeda H (2015) Virtual CT morphometry of lower limb long bones for estimation of the sex and stature using postmortem Japanese adult data in forensic identification. Int J Legal Med 129(5):1173-1182

Hunt DR, Albanese J (2005) History and demographic composition of the Robert J. Terry anatomical collection. Am J Phys Anthropol 127(4):406-417

Jeong Y, Jantz LM (2016) Developing Korean-specific equations of stature estimation. Forensic Sci Int 260:105.e1-105.e11
Karakas HM, Celbis O, Harma A, Alicioglu B (2011) Total body height estimation using sacrum height in Anatolian Caucasians: multidetector computed tomography-based virtual anthropometry. Skelet Radiol 40(5):623-630

Karaman A, Teke H, Günay I, Dogan B, Bilge Y (2008) Height estimation using anthropometric measurements on $\mathrm{X}$-rays of wrist and metacarpal bones. Internet J Biol Anthropol 2(1):1-22

Krishan K, Kanchan T, DiMaggio JA (2010) A study of limb asymmetry and its effect on estimation of stature in forensic case work. Forensic Sci Int 200(13):181.e1-181.e5

Mahakkanukrauh P, Khanpetch P, Prasitwattanseree S, Vichairat K, Troy Case D (2011) Stature estimation from long bone lengths in a Thai population. Forensic Sci Int 210(1-3):279.e1-279.e7

Mall G, Hubig M, Büttner A, Kuznik J, Penning R, Graw M (2001) Sex determination and estimation of stature from the long bones of the arm. Forensic Sci Int 117(1-2):23-30

Mensforth RP, Latimer BM (1989) Hamann-Todd collection aging studies: osteoporosis fracture syndrome. Am J Phys Anthropol 80(4):461-479

Muñoz, J., M. Liñares-Iglesias, J. Suárez-Peñaranda, M. Mayo, X. Miguéns, M. Rodríguez-Calvo \& L. Concheiro 2001. Stature estimation from radiographically determined long bone length in a Spanish population sample

Pearson K (1899) Mathematical contributions to the theory of evolution. V. On the reconstruction of the stature of prehistoric races. Philos Trans R Soc Lond A 192:169-244

Petrovečki V, Mayer D, Šlaus M, Strinović D, Škavić J (2007) Prediction of stature based on radiographic measurements of cadaver long bones: a study of the croatian population*. J Forensic Sci 52(3):547-552

Radoinova D, Tenekedjiev K, Yordanov Y (2002) Stature estimation from long bone lengths in Bulgarians. HOMO 52(3):221-232

Saladin KS (2007) Anatomy and physiology: the unity of form and function. McGraw Hill International, Ohio

Sarajlić N, Cihlarž Z, Klonowski EE, Selak I (2006) Stature estimation of Bosnian male population. Bosn J Basic Med Sci 6(1):62-67

Shields, K. J. 2007. The importance of individual and population variation to human stature estimation

Torimitsu S, Makino Y, Saitoh H, Ishii N, Hayakawa M, Yajima D, Inokuchi G, Motomura A, Chiba F, Iwase H (2014a) Stature estimation in Japanese cadavers using the sacral and coccygeal length measured with multidetector computed tomography. Legal Med 16(1):14-19

Torimitsu S, Makino Y, Saitoh H, Sakuma A, Ishii N, Hayakawa M, Yajima D, Inokuchi G, Motomura A, Chiba F, Iwase H (2014b) Stature estimation based on radial and ulnar lengths using three-dimensional images from multidetector computed tomography in a Japanese population. Legal Med 16(4):181-186

Torimitsu S, Makino Y, Saitoh H, Sakuma A, Ishii N, Hayakawa M, Yajima D, Inokuchi G, Motomura A, Chiba F, Iwase H (2014c) Stature estimation in Japanese cadavers based on pelvic measurements in three-dimensional multidetector computed tomographic images. Int J Legal Med 129(3):633-639

Trotter M, Gleser GC (1952) Estimation of stature from long bones of American Whites and Negroes, pp 463-514

Trotter M, Gleser GC (1958) A re-evaluation of estimation of stature based on measurements of stature taken during life and of long bones after death. Am J Phys Anthropol 16(1):79-123

Zech W-D, Näf M, Siegmund F, Jackowski C, Lösch S (2016) Body height estimation from post-mortem CT femoral F1 measurements in a contemporary Swiss population. Legal Med 19:61-66

Zhang K, Luo Y-z, Fan F, Zheng J-q, Yang M, Li T, Pang T, Zhang J, Deng Z-h (2015) Stature estimation from sternum length using computed tomography-volume rendering technique images of western Chinese. J Forensic Legal Med 35:40-44 